\title{
Molecular Characterization of Sclerocarya birrea ICRAF Field Genebank Collections
}

\author{
Machani G Fridah", Muchugi Alice, Ngugi M Piero, Jamnadass Ramni, Omwenga I George, Kariba Robert, Mng'omba Simon and Prasad Hendre
} Department of Biochemistry and Biotechnology, Kenyatta University, 89, Magwagwa, Nairobi, Kenya 40508

*Corresponding author: Machani G Fridah, Department of Biochemistry and Biotechnology, Kenyatta University, 89, Magwagwa, Nairobi, Kenya 40508, Tel: +254704542720; E-mail: machafrida@gmail.com

Receiving date: Oct 24, 2017; Acceptance date: Nov 22, 2017; Publication date: Nov 27, 2017

Copyright: ( 2017 Fridah MG, et al. This is an open-access article distributed under the terms of the Creative Commons Attribution License, which permits unrestricted use, distribution and reproduction in any medium, provided the original author and source are credited.

\begin{abstract}
Scelerocarya birrea is an important fruit tree that is widely used by the rural populations in most regions in which it is found, for its fruits, bark, timber and even its roots. The local communities harvest the tree products from the wild with minimal attempts to grow it on-farm. The sustainability of such wild harvests is threatened by agriculture, overgrazing and overexploitation for other purposes. Therefore, the species needs urgent conservation measures in addition to selecting superior germplasm for on-farm tree management that will facilitate ease of species cultivation. This has prompted the International Center for Research in Agroforestry (ICRAF) and partners to collect and manage $S$. birrea germplasm in field genebanks as the initial step towards the species domestication and conservation. In order to effectively manage germplasm, it is important to establish the collection genetic diversity. Six ISSR markers yielded a total of 76 polymorphic bands across the 257 accessions studied. Percentage of polymorphic loci and observed heterozygosity ranged from $75 \%$ to $7.89 \%$ and $\mathrm{H}=0.362$ to $\mathrm{H}=0.043$, respectively. The partitioning of genetic diversity found a higher $(86 \% \mathrm{P}>0.001)$ intra-population variation and low inter-population variation, typical of the outcrossing nature of $S$. birrea. According to Jaccard's dissimilarity index, the highest genetic distance between accessions was 1.000 and the least genetic distance was 0.000 . Neighbour-joining clustering grouped the accessions into three major clusters and twenty probable duplicates were identified, which should be eliminated to cut down the cost of conservation. The results obtained suggest that $S$. birrea ICRAF field genebank collections have a comparatively rich gene pool and, hence, valuable for conservation of $S$. birrea. The twenty samples showing duplicates would be good for evaluating performance of this long-lived tree species in both locations.
\end{abstract}

Keywords: Genetic diversity; Sclerocarya birrea

\section{Introduction}

Scelerocarya birrea is an important fruit tree that is widely used by the rural populations in most regions in which it is found, for its fruits, bark, timber and even its roots. Studies have shown that the tree has the potential to boost nutrition, health and income security in Africa. The fruits are rich in vitamin $\mathrm{C}$ and can be eaten fresh, fermented to brew alcoholic drinks or used to make juice, jelly or jam. $S$. birrea juice surpasses orange, mango and lemon juices in vitamin $\mathrm{C}$ content. The seed kernels are rich in proteins and oil. The fruits and leaves are browsed by livestock and have a variety of medical uses and the bark is used to treat various ailments including Malaria prophylaxis [1-26].

However, the local communities harvest the tree products from the wild with minimal attempts to grow it on-farm. The sustainability of such wild harvests is threatened by agriculture, overgrazing and overexploitation for other purposes $[9,10]$. Therefore, the species needs urgent conservation measures in addition to selecting superior germplasm for on-farm tree management that will facilitate ease of species cultivation.

$S$. birrea seeds are semi-recalcitrant and cannot be maintained in a seed bank for a long period. This has prompted the ICARF and partners to collect and manage $S$. birrea germplasm in field genebanks in Tanzania, Malawi and Zambia, as the initial step for its domestication and conservation. However, maintenance of field genebanks is costly because trees take up large space and are prone to human and environmental threats. There is a need to make an informed decision on what stands should continue being managed as core collections in a field genebank as well as ensuring that diverse material is conserved.

The provenance trial data have shown great variability in morphological traits across populations $[14,16,20]$. The mother trees were characterized using RAPD [9] and showed significant variation within and among the populations. There is, therefore, the likelihood that even seedlings raised from this collection will also express high diversity. This study aimed at genetically characterizing $S$. birrea ICRAF field genebank collections.

\section{Materials and Methods}

\section{Plant materials and population sampling}

A total of 161 and 96 leaf samples were collected from Malawi and Tanzania, respectively across nine populations and 44 sub-populations. Selection of the mother trees from which the germplasm was collected for the stand establishment was based on the phenotypic and superiority in fruit taste and size as recorded from the local communities. Sampling was done for trees at least $100 \mathrm{~m}$ apart to minimize excessive neighbourhood inbreeding with each population having a bulk of 9 to 10 mother trees. 
Citation: Fridah MG, Alice M, Piero NM, Ramni J, George OI, et al. (2017) Molecular Characterization of Sclerocarya birrea ICRAF Field Genebank Collections. J Phylogenetics Evol Biol 5: 190. doi:10.4172/2329-9002.1000190

Page 2 of 8

\section{DNA extraction and ISSR amplification}

Total genomic DNA was extracted from each of silica-dried leaf samples using MN NucleoSpin Plant 11 kit (Macherey-Nagel, Germany), following the manufacturer's instructions of the manufacturer, with minor modifications. The extracted genomic DNA was quantified on 0.8 percent agarose gel electrophoresis to determine its quantity. Six ISSR primers (Table 1) were used to genotype $S$. birrea accessions. The PCR amplification was carried out in a total volume of $20 \mu \mathrm{l}$, consisting of $10.6 \mu \mathrm{l}$ of deionized water, $4 \mu \mathrm{l}$ of MyTaq buffer, (Bioline, UK), 0.4 units of MyTaq polymerase, (Bioline, UK) $2 \mu \mathrm{l}$ of primer and $30 \mathrm{ng}$ of template DNA. A touchdown PCR reaction was conducted using with the following thermal cycling program: 1 cycle of initial denaturation at $95^{\circ} \mathrm{C}$ for $3 \mathrm{~min} ; 12$ cycles of $95^{\circ} \mathrm{C}$ for $1 \mathrm{~min}$, $58^{\circ} \mathrm{C}$ to $47^{\circ} \mathrm{C}$ for 30 seconds at a decreasing rate of $1^{\circ} \mathrm{C}$ per cycle and $72^{\circ} \mathrm{C}$ for $1 \mathrm{~min}$. The third stage consisted of 23 cycles of $95^{\circ} \mathrm{C}$ for 1 min, $47^{\circ} \mathrm{C}$ for 30 seconds and $72^{\circ} \mathrm{C}$ for $1 \mathrm{~min}$. Stage four consisted of 1 cycle of final extension at $72^{\circ} \mathrm{C}$ for $7 \mathrm{~min}$ and a holding step at $15^{\circ} \mathrm{C}$.

\section{Data analysis}

The PCR products were resolved on 2\% agarose gel electrophoresis and scored manually. Distinct, reproducible, well resolved fragments were scored as present ( 1 ) or absent ( 0 ) for each ISSR reaction and data were displayed as a binary matrix in MS Excel. A standard band scoring size was set at a range of $100 \mathrm{bp}$ to $2000 \mathrm{bp}$. GenAlex version 6.5 [21] statistical software was then used to compute the number of alleles, Nei's genetic diversity and percent polymorphic loci. Powermarker version 3.25 [11] was used to calculate allele number, major allele frequencies, gene diversity and polymorphic information content. Observed heterozygosity was computed using Tools for Population Genetic Analysis (TFPGA) version 1.3 [13]. Jaccard's dissimilarity index was computed and a phylogenetic tree constructed using DARwin version 6.0 [22].

\begin{tabular}{|c|c|c|}
\hline MARKER & SEQUENCE (5'-3') & ANCHOR \\
\hline U4576C07 & CACGACGTTGTAAAACGACCACACACACACACACAA & $(A C) 7,3^{\prime} A A$ \\
\hline U4576C08 & CACGACGTTGTAAAACGACACACACACACACACACT & (AC)9, 3' T \\
\hline U4576C09 & CACGACGTTGTAAAACGACAGAGAGAGAGAGAGAGYT & $(A G) 8,3^{\prime} Y T$ \\
\hline U4576D04 & CACGACGTTGTAAAACGACCACACACACACACACARG & (CA)8, 3'RG \\
\hline U4576D05 & CACGACGTTGTAAAACGACCACACACACACACACACAYG & (CA)9, 3'YG \\
\hline U4576D07 & CACGACGTTGTAAAACGACACACACACACACACACYA & $(\mathrm{AC}) 8,3^{\prime} Y A$ \\
\hline
\end{tabular}

Table 1: Sequences of the six ISSR markers used for characterization of $S$. birrea ICRAF field genebank collections

\section{Results}

\section{ISSR polymorphism}

The six markers yielded a total of 76 polymorphic bands across the 257 accessions ranging from 100 base pairs to 2000 base pairs (Figure
1). The number of amplification products ranged from one to nine products per accession. Accessions T5-R1-25, T2-R1-49 and T10R2-89 did not amplify with U4576C08, but amplified with U4576C09. 
Citation: Fridah MG, Alice M, Piero NM, Ramni J, George OI, et al. (2017) Molecular Characterization of Sclerocarya birrea ICRAF Field Genebank Collections. J Phylogenetics Evol Biol 5: 190. doi:10.4172/2329-9002.1000190

Page 3 of 8

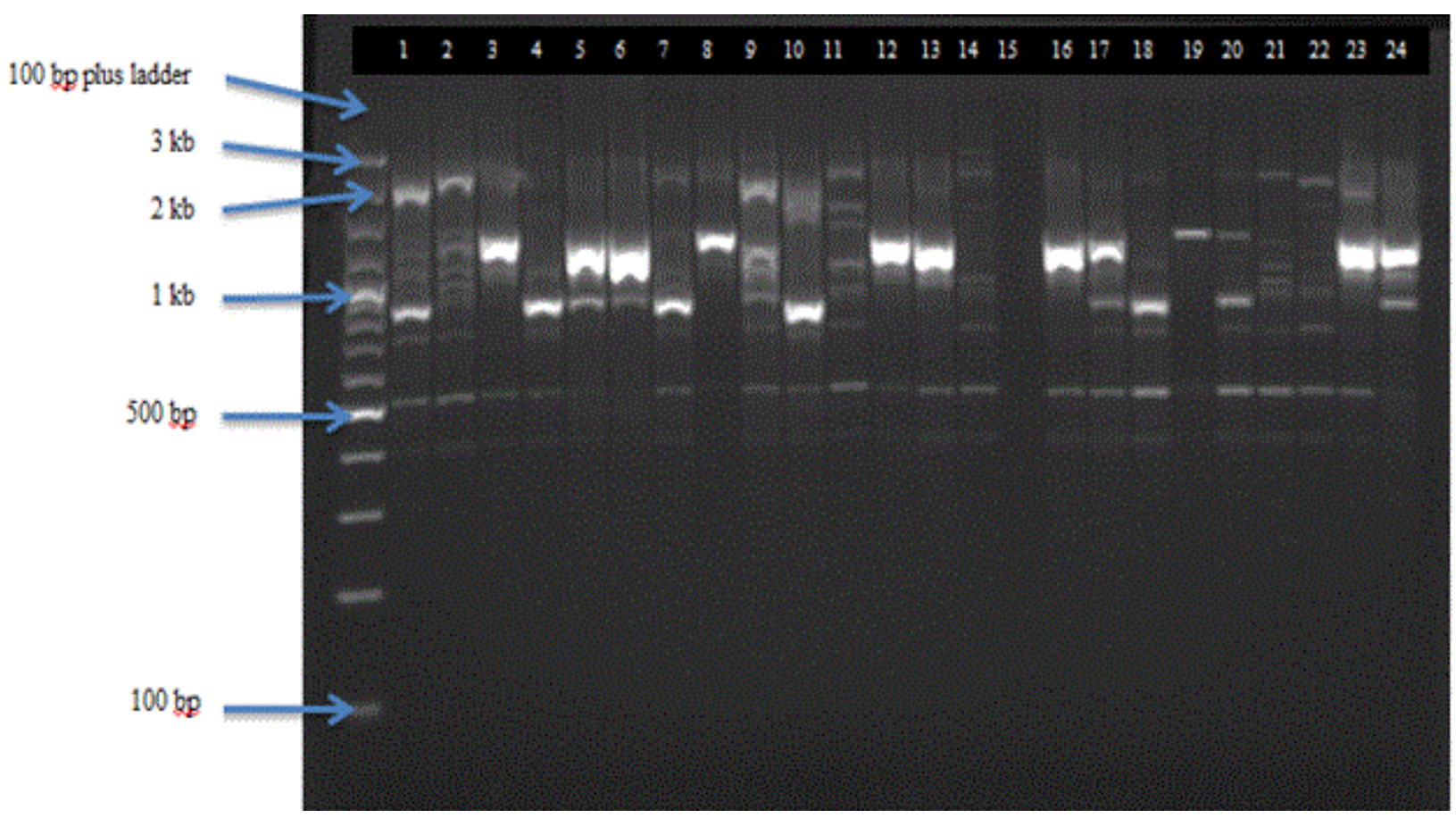

Figure 1: 2\% agarose gel image showing PCR amplification products of 24 samples from $\quad$ Tanzania provenance trial using primer U4576C08

The mean number of alleles was 2.066 ; the number of effective alleles ranged from 1.041 to 1.380 ; and Major allele frequencies ranged from 0.730 to 0.882 (Table 2). Average PIC was 0.236 .

\begin{tabular}{|l|l|l|l|}
\hline Marker type & Major allele frequency & Allele no & PIC \\
\hline U4576C07 & 0.882 & 2.000 & 0.154 \\
U4576C08 & 0.783 & 2.063 & 0.244 \\
U4576C09 & 0.730 & 2.083 & 0.271 \\
U4576D04 & 0.816 & 2.091 & 0.222 \\
U4576D05 & 0.793 & 2.071 & 0.239 \\
U4576D07 & 0.765 & 2.083 & 0.273 \\
\hline Mean & 0.793 & 2.066 & 0.236 \\
\hline
\end{tabular}

Table 2: Major allele frequencies, allele number and polymorphic information content of 257 S. birrea ICRAF field genebank accessions.

\section{Gene diversity}

The mean percent polymorphic loci were $51.67 \%$, with highest in Choma-M accessions (75\%) and the least in Mialo-Kondoa-M (7.89\%) accessions (Table 3). Average heterozygosity per population ranged from $\mathrm{H}=0.362$, in Choma- $\mathrm{M}$ to $\mathrm{H}=0.043$, in Mialo-Kondoa-M, with a mean of $\mathrm{H}=0.242$. Expected heterozygosity ranged from $\mathrm{HE}=0.246$ to $\mathrm{HE}=0.031$ (Table 3).

\begin{tabular}{|l|l|l|l|c|}
\hline Populations & Sample size & HO & HE & 99\% Criterion polymorphism \\
\hline Tutume-T & 5.000 & 0.236 & $0.181 \pm 0.024$ & 51.32 \\
\hline Marulamantsi-T & 5.000 & 0.179 & $0.143 \pm 0.023$ & 39.47 \\
\hline Kalimbenza-T & 7.000 & 0.268 & $0.226 \pm 0.024$ & 63.16 \\
\hline Oshikondilogo-T & 6.000 & 0.194 & $0.147 \pm 0.022$ & 43.42 \\
\hline
\end{tabular}


Citation: Fridah MG, Alice M, Piero NM, Ramni J, George OI, et al. (2017) Molecular Characterization of Sclerocarya birrea ICRAF Field Genebank Collections. J Phylogenetics Evol Biol 5: 190. doi:10.4172/2329-9002.1000190

Page 4 of 8

\begin{tabular}{|c|c|c|c|c|}
\hline Ohangwena-T & 7.000 & 0.271 & $0.198 \pm 0.023$ & 63.16 \\
\hline Manyonyaneni-T & 6.000 & 0.268 & $0.222 \pm 0.024$ & 61.84 \\
\hline Makata-T & 6.000 & 0.24 & $0.238 \pm 0.026$ & 60.53 \\
\hline Wami-T & 5.000 & 0.278 & $0.222 \pm 0.024$ & 61.84 \\
\hline Zimmasv-T & 7.000 & 0.194 & $0.148 \pm 0.023$ & 44.74 \\
\hline Zimmase-T & 7.000 & 0.178 & $0.134 \pm 0.022$ & 40.79 \\
\hline Zimman-T & 6.000 & 0.178 & $0.144 \pm 0.023$ & 42.11 \\
\hline Zimmatn-T & 5.000 & 0.099 & $0.094 \pm 0.021$ & 23.68 \\
\hline Zimmants-T & 7.000 & 0.264 & $0.234 \pm 0.024$ & 63.16 \\
\hline Chikawawa-T & 2.000 & 0.167 & $0.167 \pm 0.029$ & 30.26 \\
\hline Mangochi-T & 6.000 & 0.166 & $0.145 \pm 0.024$ & 39.47 \\
\hline Ntcheu-T & 4.000 & 0.095 & $0.087 \pm 0.021$ & 21.05 \\
\hline Mpandamatonga- $T$ & 5.000 & 0.151 & $0.148 \pm 0.025$ & 36.84 \\
\hline Missira-M & 9.000 & 0.332 & $0.201 \pm 0.020$ & 71.05 \\
\hline Chikwawa-M & 6.000 & 0.214 & $0.144 \pm 0.021$ & 44.74 \\
\hline Mangochi-M & 8.000 & 0.291 & $0.171 \pm 0.020$ & 60.53 \\
\hline Ntcheu-M & 7.000 & 0.303 & $0.146 \pm 0.017$ & 61.84 \\
\hline Rumphi-M & 5.000 & 0.295 & $0.199 \pm 0.022$ & 60.53 \\
\hline Marracuene-M & 7.000 & 0.289 & $0.147 \pm 0.017$ & 56.59 \\
\hline Magunde-M & 11.000 & 0.343 & $0.187 \pm 0.018$ & 72.37 \\
\hline Moamba-M & 6.000 & 0.252 & $0.210 \pm 0.024$ & 57.89 \\
\hline Oshikondilongo-M & 6.000 & 0.297 & $0.170 \pm 0.020$ & 59.21 \\
\hline Ohangwena-M & 5.000 & 0.309 & $0.246 \pm 0.024$ & 65.79 \\
\hline Kalimbeza-M & 5.000 & 0.245 & $0.187 \pm 0.024$ & 51.32 \\
\hline Kalanga-M & 8.000 & 0.282 & $0.218 \pm 0.023$ & 64.47 \\
\hline Mkata Morogoro-M & 2.000 & 0.138 & $0.138 \pm 0.028$ & 25 \\
\hline Ubena Morogoro-M & 3.000 & 0.12 & $0.079 \pm 0.018$ & 21.053 \\
\hline Wami Coast Region-M & 3.000 & 0.172 & $0.139 \pm 0.024$ & 32.89 \\
\hline Magamba Handeni-M & 8.000 & 0.306 & $0.182 \pm 0.020$ & 63.16 \\
\hline Chigongwe Dodoma-M & 3.000 & 0.222 & $0.189 \pm 0.026$ & 43.42 \\
\hline Mialo Kondoa-M & 3.000 & 0.043 & $0.031 \pm 0.013$ & 7.89 \\
\hline Mandimu Singida-M & 2.000 & 0.116 & $0.116 \pm 0.026$ & 21.05 \\
\hline Ngundu-M & 7.000 & 0.354 & $0.212 \pm 0.020$ & 73.68 \\
\hline Mudzi-M & 6.000 & 0.297 & $0.173 \pm 0.020$ & 59.21 \\
\hline Biriwiri-M & 6.000 & 0.304 & $0.203 \pm 0.022$ & 63.16 \\
\hline Muzarabani-M & 7.000 & 0.353 & $0.215 \pm 0.020$ & 72.37 \\
\hline
\end{tabular}


Citation: Fridah MG, Alice M, Piero NM, Ramni J, George OI, et al. (2017) Molecular Characterization of Sclerocarya birrea ICRAF Field Genebank Collections. J Phylogenetics Evol Biol 5: 190. doi:10.4172/2329-9002.1000190

Page 5 of 8

\begin{tabular}{|l|l|l|l|l|}
\hline Matebeleland N-M & 8.000 & 0.312 & $0.195 \pm 0.021$ & 65.79 \\
\hline Matebeleland S-M & 6.000 & 0.318 & $0.196 \pm 0.020$ & 64.47 \\
\hline Siavonga-M & 7.000 & 0.35 & $0.200 \pm 0.019$ & 72.37 \\
\hline Choma-M & 7.000 & 0.362 & $0.216 \pm 0.020$ & 75 \\
\hline Mean & 5.841 & 0.242 & $0.172 \pm 0.022$ & 51.67 \\
\hline
\end{tabular}

Table 3: Summaries of measures of gene diversity for $S$. birrea accession in Tanzania and Malawi provenance trials. NB: T-Tanzania provenance trial; M-Malawi provenance trial.

\section{Phylogenetic relationships}

The genetic distance as measured by Jaccard's dissimilarity index ranged from 1.000 to 0.000 (data not shown). The accessions clustered into three major groups, the first with 224, second 30 and third with only 3 accessions. There was a major split between accessions planted in Tanzania and those planted in Malawi within the first major cluster.
Eighteen 18 accessions; ML2-7, ML2-10, ML3-7, MZ1-2, MZ1-9a, MZ1-9b, MZ2-6, N1-1, N1-4, T4-4, T8-1, T8-6, Z2-25774, Z3-25792, Z5-25829, ZA2-9, ZA3-1 and ZA3-5 clustered together, (Figure 2). The nodes of the phylogenetic tree branches, constructed from 1,000 bootstraps, were supported by values ranging from 50 to 97 percent.

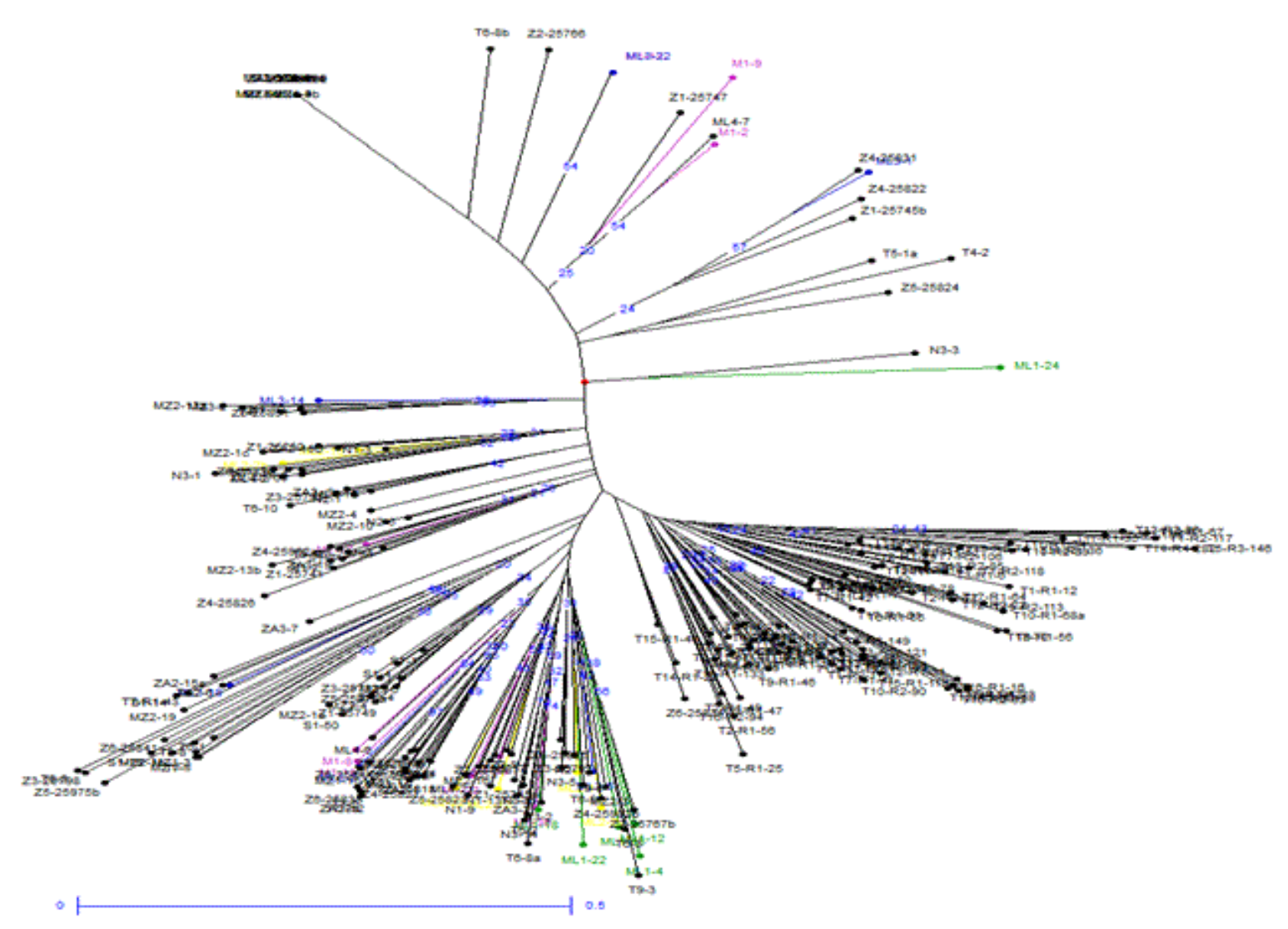

Figure 2: Dendrogram showing phylogenetic relationships among 257 S. birrea ICRAF field six ISSR primers.

A scatter plot was generated based on Nei's 1987 genetic distances (Figure 3). The relationships of $S$. birrea accessions on the Principle Component Analysis (PCoA) support the UPGMA clustering. The first three axes show $17.88 \%, 13.39 \%$ and $7.26 \%$ of the variance, respectively. The PC1 coordinates contained clusters of accessions mainly in Malawi while the PC2 coordinates consist of predominantly 
Citation: Fridah MG, Alice M, Piero NM, Ramni J, George OI, et al. (2017) Molecular Characterization of Sclerocarya birrea ICRAF Field

accessions from Tanzania, revealing the major split between accessions

conserved in Tanzania and those in Malawi provenances.

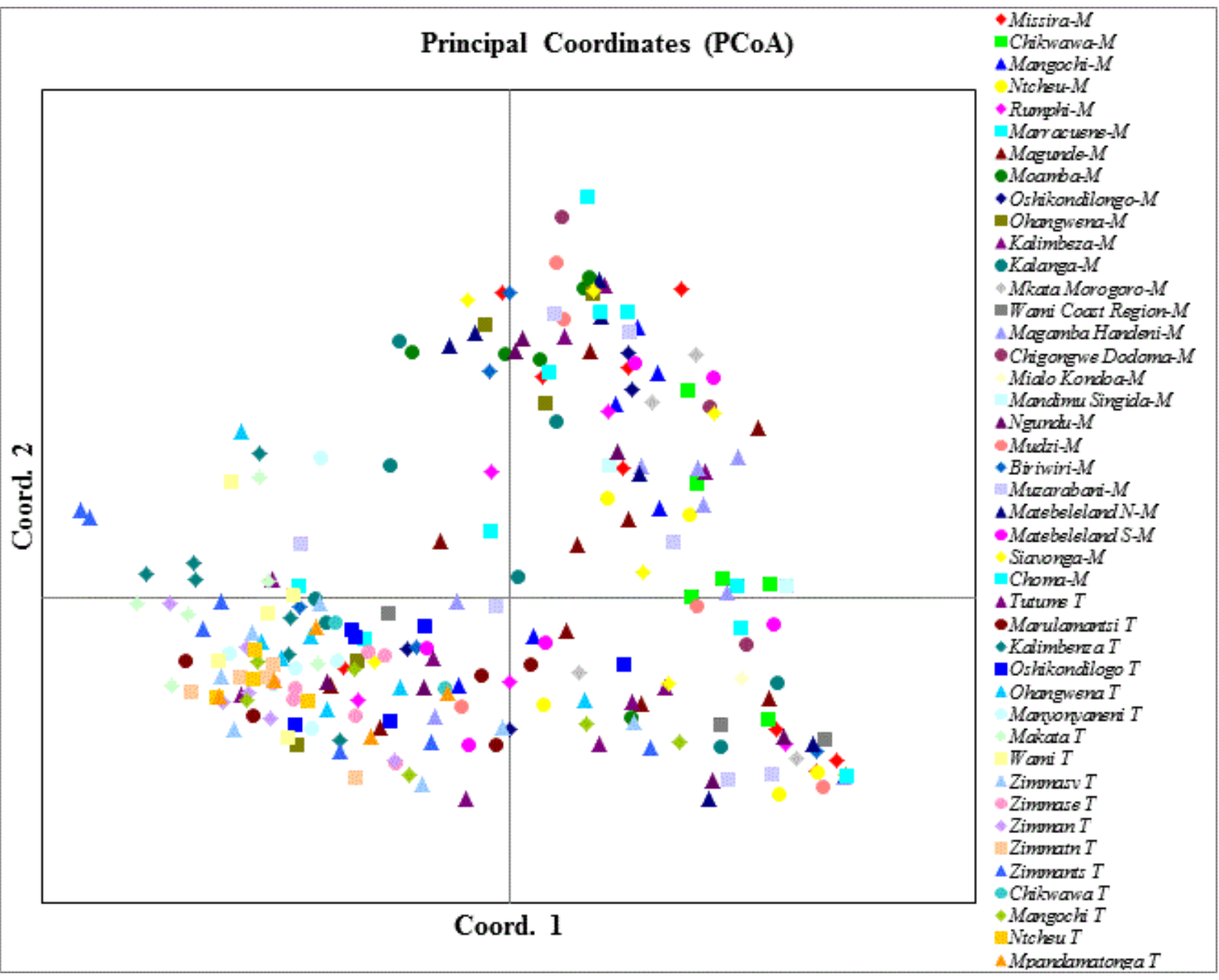

Figure 3: Principal coordinate analysis of 257 S. birrea ICRAF field Partitioning of genetic variation

Unstructured analysis of molecular variance based on forty-four genebank accessions as revealed by six ISSR markers populations indicated more variation $(86 \%, \mathrm{P}>0.001)$ within populations and little variation $(14 \%, \mathrm{P}>0.001)$ among the populations (Table 4 and Figure 4).

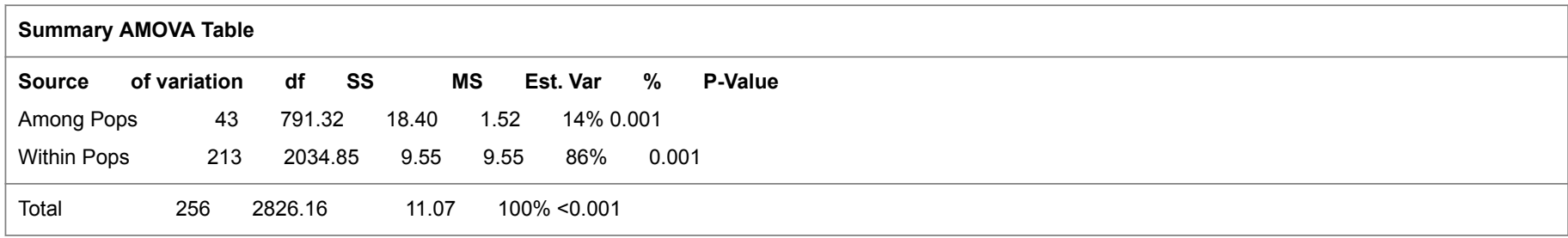

Table 4: Summary AMOVA for 44 S. birrea ICRAF field genebank populations as revealed by six ISSR markers. 


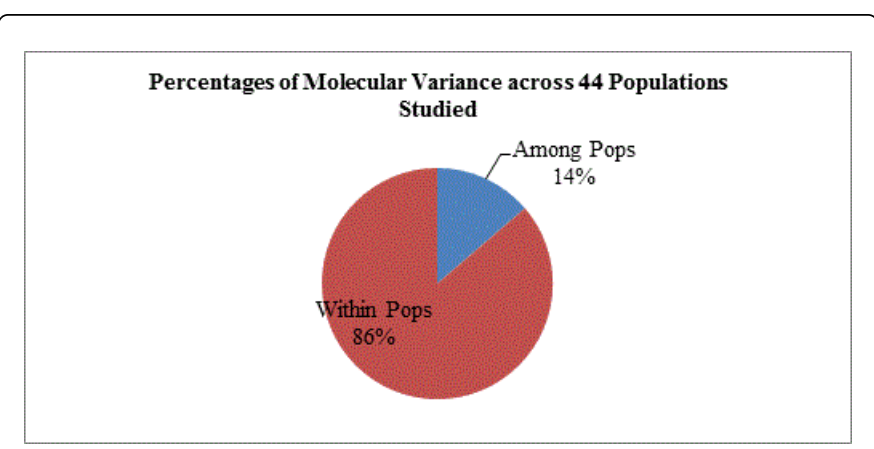

Figure 4: Percent partitioning among and within 44 S. birrea ICRAF field genebank populations as revealed by six ISSR markers.

\section{Discussion}

In the present study on $S$. birrea, the 76 loci were amplified and found to be highly polymorphic, displaying up to 9 alleles per sample. This is in agreement with the dominant multilocus nature of Intersimple sequence repeat markers [19,20]. Lack of amplification with primer $\mathrm{U} 4576 \mathrm{C} 08$ in some accessions can be attributed to lack of the $\mathrm{AC}$ repeat regions or mutation in the $\mathrm{AC}$ repeat regions in those accessions. Besides, lack of the $\mathrm{T}$ anchoring nucleotide at the end of $\mathrm{AC}$ repeat regions in those accessions could have also prevented any amplification.

Values of gene diversity in the current study were extremely variable with Mialo Kondoa-M having the least value because of varying sample sizes and different mother populations. The current study found that accessions in Malawi were more diverse (greater \%polymorphism and heterozygosity) compared to those in Tanzania which can be attributed to the selection of planting materials from the nurseries. Differences may have been compounded by biased sampling of planting materials from the nurseries and the small sample sizes used in the study. It would be important to include all samples in the stands, as well as the replicates to conclude on the genetic variation among the mother plants and the plants raised from their seeds. The proportion of heterozygous trees was higher than expected because $S$. birrea is outcrossing and, $S$. birrea provenance trials were established by mixing accessions from previously isolated populations [24].

Higher levels of polymorphism obtained in the present study are in line with those reported on natural populations of $S$. birrea in Sudan and Burkina Faso [1,10] (58.8\% and 53.03\%, respectively). Higher levels of polymorphism in the present study are also consistent with those reported for Mangifera indica [26] and Anacardium occidentale [3] close relatives of $S$. birrea, using the same type of primers. The current study found low Nei's genetic diversity compared to those reported for Tamarindus indica $(\mathrm{H}=0.350)$ [4] and Tectona grandis $(\mathrm{H}=0.36)$ [2] using similar primers. Nei's genetic diversity in the present study was in line with that previously reported by Moganedi et al [15] and Kando et al. [10] on S. birrea. Higher levels of polymorphism suggest high genetic differentiation within populations [25]. The results of the present study show low levels of genetic diversity. This suggests a possibility of genetic erosion due to habitat loss that is ascribed to anthropogenic factors acting on the mother populations long before the time of collections [10]. Selection of superior mother trees might have also reduced polymorphism as the field genebanks were established by a very small number of seeds from the mother trees. The phenotypic traits used as a criterial to select the mother trees are also subject to ecological variations therefore not environmentally neutral as compared to genetic marker selection and perhaps some of these characters observed in some trees might not have been true superior ones.

In comparison to the mother population, Kadu et al. [9] reported low genetic diversity $(\mathrm{H}=0.131)$ of the original mother populations from some of the regions sampled. ICRAF field genebank $S$. birrea collection was more diverse $(\mathrm{H}=0.241)$ than the mother populations, which is expected for high outcrossing levels of tropical trees, such as $S$. birrea. Incomplete sampling of the mother populations due to a small geographical sampling range employed and small sample size in mother populations can also explain the difference. A different marker system, which produces different band patterns from ISSRs, was used to characterize the mother populations. ICRAF field genebank collections were also established from germplasm selected based on superiority in morphological traits, a biased sampling that is expected to produce a different pattern of DNA polymorphism. The difference in genetic diversity is also expected because the current populations consist of half-sibling families that share half of the genetic information with the mother trees and half with the pollen sources.

Management schemes of ICRAF field genebank $S$. birrea collections and domestication programs will depend on the amount and the structuring of its genetic diversity. The current partitioning of genetic diversity found higher within population variation $(86 \%, \mathrm{P}>0.001)$, which is expected because $S$. birrea is dioecious with little or no selfing. High within population genetic diversity indicates that $S$. birrea accessions in ICRAF field genebanks have high genetic variation. This structuring of genetic diversity is consistent with those reported previously for $S$. birrea $[1,9,10,15]$.

Most accessions were genetically distinct, reflecting the tree-to-tree variation in morphological traits reported for $S$. birrea $[14,16,20]$. This high genetic variation among the studied accessions is because they are half-sibs that share genetic information from only one parent. Results of this study suggest that $S$. birrea accessions are genetically diverse.

Neighbor-joining phylogenetic tree revealed that accessions planted in Tanzania have greater similarity to each other despite the geographical distance of the mother populations. Accessions from Manyonyaneni and Tutume share a common ancestor, in agreement with the clustering of mother populations by Kadu et al. [9], in which these populations clustered together. However, the number of populations analyzed by Kadu et al [9] were fewer than those characterized in the present study. Kadu et al [9] also clustered populations rather than individual trees. The current study, therefore, provides the first evidence for the relationship among $S$. birrea accessions in ICRAF field genebank. The bootstrap values were very low suggesting that only a few characters support those nodes. The large dataset could have made bootstrapping to fall victim of bias and give low values. The observed branches could, therefore, be due to a single extreme data point.

One of the options to improve the composition of $S$. birrea collections and improve conservation of its germplasm is the identification and elimination of duplicate materials. Germplasm collections invariably contain duplicate accessions, both within and between genebanks. The results of this study identified twenty probable duplicates within Malawi field genebank which should be eliminated 
because they do not contribute to the genetic diversity of the collection, but require a budget for maintenance. Duplicates might occur within collections because of common errors in information transfer and registry of identical material under different identifiers. The mother populations from which seeds were collected for the establishment of $S$. birrea ICRAF field genebanks had not been genetically characterized by the time of those collections. There is a chance that populations were genetically identical, hence the duplicates identified in this study. High numbers of duplicates were identified, hence, there is need to eliminate these redundancies so as to cut down the cost of conservation. However, the twenty samples showing duplicates would be good for evaluating performance of this long-lived tree species in both locations.

\section{Conclusion}

S. birrea accessions in ICRAF field genebank have a comparatively rich gene pool, hence, valuable for conservation of the species. Seeds harvested from these populations will retain the fitness superiority of the inter-population outbreeding, a positive effect on the aggregate measure of the species' fitness to climate change. However, the subset of populations that hold very little genetic diversity are insufficient reservoirs of genetic diversity and would be inappropriate as sole sources of germplasm for introduction of $S$. birrea into agroforestry. Therefore, keeping germplasm across multiple trees and populations will be required for any future regeneration, tree breeding and improvement programs to maintain genetically viable ex situ collections. Choma-M, Missira-M, Ntcheu-M, Magunde, OhangwenaM, Magamba-M, Ngundu-M, Muzarabani-M, Matembeleland-N-M, Matembeleland-S-M and Siavonga-M populations should be the focus of conservation efforts and resources. There is also a need to monitor the identified duplicate accessions for production to assess the influence of locations on production.

\section{Acknowledgements}

This work was supported by CGIAR Research Program for Genebanks (Managing and Sustaining Crop Collection) funds through ICRAF Genebank. Technical support was provided by ICRAF Molecular and Genomics Laboratory.

\section{References}

1. Abdelkheir RM, Hamza NB, Khalil AM, Warrag EI (2011) Genetic variation within and among five natural populations of endangered Sclerocarya birrea (A. Rich) subsp. birrea in Sudan. J Biotechnol 10: 5452-5460.

2. Ansari SA, Narayanan C, Wali SA, Kumar R, Shukla N, et al. (2012) ISSR markers for analysis of molecular diversity and genetic structure of Indian teak (Tectona grandis L.f.) populations. Ann For Res 55: 11-23.

3. Dasmohapatra R, Rath S, Pradhan B, Rout GR (2014) Molecular and agro morphological assessment of cashew (Anacardium occidentale L.) genotypes of India. J Appl Hortic 16: 215-221.

4. Diallo BO, Joly HI, McKey D, Hossaert-Mckey M, Chevallier MH (2007) Genetic diversity of Tamarindus indica populations: Any clues on the origin from its current distribution. Afr J Biotechnol 6: 853-860.

5. Dlamini CS (2011) Provenance and family variation in seed mass and fruit composition in Sclerocarya birrea sub-species caffra. J Hortic For 3: 286-293.
6. Gouwakinnou GN, Lykke AM, Assogbadjo AE, Sinsin B (2011) Local knowledge, pattern and diversity of use of Sclerocarya birrea. J Ethnobiol Ethnomed 7: 8.

7. Hamidou A, Iro GD, Boube M, Malick ST, Mahamane A (2014) Potential germination and initial growth of Sclerocarya birrea (A. Rich.) Hochst in Niger. J Appl Biosci 76: 6433-6443.

8. Hiwilepo-van Hal P, Bille PG, Verkerk R, van Boekel MAJS, Dekker M (2014) A review of the proximate composition and nutritional value of $S$. birrea (Sclerocarya birrea subsp. caffra). Phytochem Rev 13: 881-892.

9. Kadu CAC, Imbuga M, Jamnadass R, Dawson IK (2006) Genetic management of indigenous fruit trees in southern Africa: A case study of Sclerocarya birrea based on nuclear and chloroplast variation. S Afr J Bot 72: 421-427.

10. Kando PB, Bisseye C, Nanema RK, Traore ER, Ye H, et al. (2012) Genetic diversity of Sclerocarya birrea subspecies birrea populations in Burkina Faso detected by RAPDs. Afr J Biotechnol 11: 99-108.

11. Liu K, Muse SV (2005) Powermarker: An integrated analysis environment for genetic marker analysis. Bioinformatics 21:2128-2129.

12. Maroyi A (2013) Traditional use of medicinal plants in south-central Zimbabwe: Review and perspectives. J Ethnobiol Ethnomed 9: 31.

13. Miller MP (1997) Tools for Population Genetic Analyses (TFPGA): A Windows ${ }^{\circ}$ program for the analysis of allozyme and molecular population genetic data. J Ethnobiol Ethnomed 9: 33

14. Mkwezalamba I, Munthali CRY, Missanjo E (2015) Phenotypic variation in fruit morphology among provenances of Sclerocarya birrea (A. Rich.) Hochst. Int J For Res.

15. Moganedi K, Sibara M, Grobler P, Goyvaerts E (2011) An assessment of genetic diversity among $S$. birrea populations using the amplified fragment length polymorphism (AFLP) technique. Afr J Agric Res 6: 790-797.

16. Msukwa V, Muthali RYC, Missanjo E, Chilima ZC, Mng'omba WS, et al. (2016) Growth performance and fruit production of Sclerocarya birrea (A. Rich.) Hochst. provenances in Malawi. Int J Sci Res in Agric Sci 3: 042-049.

17. Muok BO, Khumalo SG, Tadesse W, Alem Sh (2011) Sclerocarya birrea, $S$ birrea. conservation and sustainable use of genetic resources of priority food tree species in sub-Saharan Africa. Biodiversity International, Rome, Italy.

18. Nei M (1978) Estimation of average heterozozygosity and genetic distance from a small number of individuals. Genetics 89: 583-590.

19. Ng WL, Tan SG (2015) Inter-simple sequence repeat (ISSR) markers区: Are we doing it right. ASM Sci J 9: 30-39.

20. Nyoka BI, Chanyenga T, Mngomba SA, Akinnifesi FK, Sagona W (2015) Variation in growth and fruit yield of populations of Sclerocarya birrea (A. Rich.) Hochst. Agroforestry Systems 89: 397-407.

21. Peakall R, Smouse PE (2012) GenAlEx 6.5: genetic analysis in Excel. Population genetic software for teaching and research-an update. Bioinformatics 28: 2537-2539.

22. Perrier X, Jacquemoud-Collet JP (2006) DARwin software, http:// darwin.cirad.fr/darwin.

23. Reddy MP, Sarla N, Siddiq EA (2002) Inter simple sequence repeat (ISSR) polymorphism and its application in plant breeding. Euphytica 128: 9-17.

24. Sole-Cava A, Russo CAM, Thorpe JP (2013) Marine Genetics: Volume 144 of Developments in Hydrobiology. Springer Science and Business Media.

25. Sreekumar VB, Renuka C (2006) Assessment of genetic diversity in Calamus thwaitesii BECC. (Arecaceae) using RAPD markers. Biochemical Systematics and Ecology 34: 397-405.

26. Tomar RS, Gajera HP, Viradiya RR, Patel SV, Golakiya BA (2011) Phylogenetic relationship among Mango (Mangifera indica L.) Landraces of Saurashtra based on DNA fingerprinting. J Hortic For 3: 379-385. 